\section{JTI}

JOURNAL OF

TRAUMA AND INJURY

\title{
Alcohol Intoxication and Glasgow Coma Scale Scores in Patients with Head Trauma
}

\author{
Jisoo Park, M.D. ${ }^{1}$, Taejin Park, M.D. ${ }^{1}$, Jung-In Ko, M.D. ${ }^{1}$, Woonhyung Yeo, M.D. ${ }^{2}$ \\ ${ }^{1}$ Department of Emergency Medicine, National Medical Center, Seoul, Korea \\ ${ }^{2}$ Department of Emergency Medicine, Seongnam Citizens Medical Center, Seongnam, \\ Korea
}

Received: August 14, 2020

Revised: September 27, 2020

Accepted: October 12, 2020

\section{Correspondence to}

Woonhyung Yeo, M.D.

Department of Emergency Medicine, Seongnam Citizens Medical Center,

10 Sujeong-ro 171beon-gil, Sujeong-gu, Seongnam 13290, Korea

Tel: $+82-31-738-7303$

Fax: +82-31-738-7328

E-mail:emdryo@naver.com Above $\geq 150 \mathrm{mg} / \mathrm{dL}$, higher BACs showed significant odds ratios for a lower GCS score.
Purpose: Alcohol intoxication is commonly associated with traumatic brain injury (TBI), but the influence of alcohol on the Glasgow Coma Scale (GCS) score remains unclear. This study investigates the effects of blood alcohol concentration (BAC) on the GCS score in head trauma patients with alcohol intoxication.

Methods: In total, 369 head trauma patients with alcohol intoxication in a 1-year period were retrospectively analyzed. The patients underwent head computed tomography and had a BAC $\geq 80 \mathrm{mg} / \mathrm{dL}$. Patients were divided into TBI and non-TBI groups. Brain injury severity was further classified using the head Abbreviated Injury Score (AIS). The effects according to 5 BAC groups were examined.

Results: The TBI group consisted of 64 patients (16.2\%). The mean BAC was significantly higher in the non-TBI group $(293.4 \pm 87.3 \mathrm{mg} / \mathrm{dL})$ than in the TBI group $(242.8 \pm 89.9 \mathrm{mg} / \mathrm{dL})$. The mean GCS score was significantly lower in the TBI group $(10.3 \pm 4.6)$ than in the non-TBI group (13.0 \pm 2.5$)$. A higher BAC showed a significant association with a lower mean GCS score in the TBI group, but not in the non-TBI group. Conclusions: The influence of alcohol in patients with head trauma depended on the presence of a brain injury. An association between a higher BAC and a lower GCS score was only observed in patients with TBI. Therefore, if a severe brain injury is suspected based on a GCS evaluation in patients with alcohol intoxication, prompt diagnosis and intensive care should be performed without delay.

Keywords: Alcohols; Traumatic brain injury; Glasgow Coma Scale; Abbreviated Injury Scale

(http://creativecommons.org/licenses/by-nc/4.0/) which permits unrestricted noncommercial use, distribution, and reproduction in any medium, provided the original work is properly cited. 


\section{INTRODUCTION}

Traumatic brain injury (TBI) is a major cause of mortality and permanent disability in patients with trauma admitted to the emergency room [1-3]. TBI often leads to decreased consciousness [4], and the Glasgow Coma Scale (GCS) has been applied as a standard method to objectively judge loss of consciousness in patients with TBI [5]. Of TBI cases in the emergency department, 35-50\% are associated with alcohol intoxication [6]. Alcohol intoxication is a common clinical situation that can cause confusion when evaluating the GCS in patients with head trauma. Alcohol acts as a central nervous system (CNS) depressant, and can lead to lower levels of consciousness, stupor, coma, and even death, depending on the concentration [7]. Therefore, it is vitally important to determine whether alcohol is responsible for lowering the GCS score in patients with TBI, but research on this topic remains unclear. Several studies have found that GCS scores were decreased by alcohol [8-11]. However, other studies have also reported that the blood alcohol concentration (BAC) did not affect the GCS score [12-16].

The reason for the unclear research findings on the effect of BAC on the GCS score is that TBI often results in a low level of consciousness, and this effect differs according to the severity of the brain injury; thus, it is necessary to adjust for the severity of TBI $[8,14,15]$. Another important limiting factor is the need to evaluate the severity of alcohol intoxication and to adjust accordingly. When patients were dichotomized as intoxicated or non-intoxicated, no significant difference in the GCS score was found between the two groups, but some studies have suggested that a high BAC may impact the GCS score $[10,14]$. Therefore, it is necessary to examine the effect of alcohol on GCS scores according to the BAC. Another statistical limitation is that, as pointed out in previous studies, GCS is an ordinal variable; therefore, analysis with ordinal regression can enhance statistical power $[10,17,18]$.

This study investigated the effect of BAC on the GCS score in patients with head trauma with and without TBI. This study also aimed to adjust for brain injury severity using an ordinal regression model.

\section{METHODS}

\section{Study population}

This was a retrospective study through a review of the

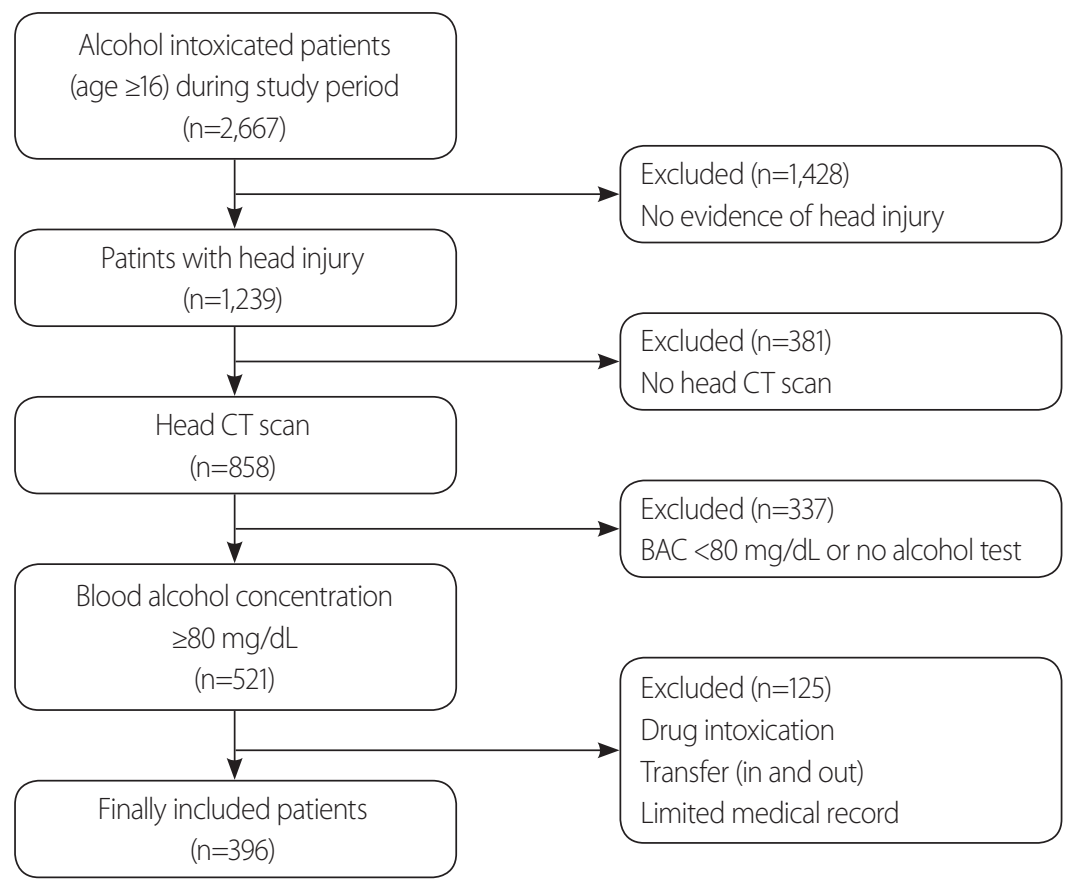

Fig. 1. Flowchart of the study population. CT: computed tomography, BAC: blood alcohol concentration. 
electronic medical records of patients with head trauma with alcohol intoxication who were treated at the National Medical Center emergency room in Seoul, Korea during a 1 -year period $(n=2,667)$. Patients were extracted by reviewing the electronic medical records from January 1, 2018, to December 31, 2018, based on chief complaints and a main diagnosis related to alcohol intoxication. The study population consisted of patients with head trauma who underwent head computed tomography (CT) and had a BAC $\geq 80 \mathrm{mg} / \mathrm{dL}$. Patients who had drug intoxication, were transferred from other institutions, were transferred to other institutions, and had missing medical records were excluded from the study, leaving 396 patients for the analysis (Fig. 1). Head trauma was defined as a case in which the patient reported a head trauma event or when there were traces of direct trauma to the face, head, and neck based on medical records. Alcohol intoxication was defined as a $\mathrm{BAC} \geq 80 \mathrm{mg} / \mathrm{dL}$, corresponding to the

Table 1. Demographic and characteristics in TBI versus non-TBI patients

\begin{tabular}{|c|c|c|c|c|}
\hline & TBI & Non-TBI & Entire & $p$-value \\
\hline Total subjects & $64(16.2)$ & $332(83.8)$ & $396(100)$ & \\
\hline Age & $55.8( \pm 12.3)$ & $53.3( \pm 12.8)$ & $53.7( \pm 12.8)$ & 0.155 \\
\hline Male & $63(96.9)$ & 305 (91.9) & $367(92.7)$ & 0.197 \\
\hline Female & $2(3.1)$ & $27(8.1)$ & $29(7.3)$ & \\
\hline $\mathrm{BAC}(\mathrm{mg} / \mathrm{dL})$ & $242.8( \pm 89.9)$ & $293.4( \pm 87.3)$ & $285.3( \pm 89.6)$ & $<0.001$ \\
\hline$<100$ & $7(10.9)$ & $6(1.8)$ & $13(3.3)$ & 0.002 \\
\hline 100 to $<150$ & $5(7.8)$ & $17(5.1)$ & $22(5.6)$ & 0.375 \\
\hline 150 to $<250$ & $19(29.7)$ & $78(23.5)$ & $97(24.5)$ & 0.341 \\
\hline 250 to $<300$ & $16(25.0)$ & $72(21.7)$ & 88 (22.2) & 0.622 \\
\hline$\geq 300$ & 17 (26.6) & $159(47.9)$ & $176(44.4)$ & 0.002 \\
\hline GCS score & $10.3( \pm 4.6)$ & $13.0( \pm 2.5)$ & $12.5( \pm 3.1)$ & $<0.001$ \\
\hline 15 & $18(28.1)$ & $136(41.0)$ & 154 (38.9) & 0.068 \\
\hline $13-14$ & $11(17.2)$ & 85 (25.6) & $96(24.2)$ & 0.202 \\
\hline $9-12$ & $12(18.8)$ & $89(26.8)$ & $101(25.5)$ & 0.211 \\
\hline $3-8$ & $23(35.9)$ & $22(6.6)$ & $45(11.4)$ & $<0.001$ \\
\hline \multicolumn{5}{|l|}{ Disposition } \\
\hline Ward admission & $21(31.3)$ & $10(3.0)$ & $30(7.6)$ & $<0.001$ \\
\hline ICU admission & $35(54.7)$ & $0(0)$ & $35(8.8)$ & $<0.001$ \\
\hline ED discharge & $6(9.4)$ & $322(97.0)$ & $328(82.8)$ & $<0.001$ \\
\hline Expired & $3(4.7)$ & $0(0)$ & $3(0.8)$ & 0.004 \\
\hline \multicolumn{5}{|l|}{ Mechanism } \\
\hline Fall & $53(82.8)$ & $300(90.4)$ & $353(89.1)$ & 0.082 \\
\hline MVC & $4(6.2)$ & $7(2.1)$ & $11(2.8)$ & 0.084 \\
\hline Pedestrian struck & $6(9.4)$ & $4(1.2)$ & $10(2.5)$ & 0.002 \\
\hline Other & $1(1.6)$ & $21(6.3)$ & $22(5.6)$ & 0.227 \\
\hline \multicolumn{5}{|l|}{ Vital sign } \\
\hline $\mathrm{SBP}(\mathrm{mmHg})$ & $128.0( \pm 37.9)$ & $124.7( \pm 22.5)$ & $125.3( \pm 25.6)$ & 0.147 \\
\hline $\mathrm{DBP}(\mathrm{mmHg})$ & $77.5( \pm 22.0)$ & $77.5( \pm 14.2)$ & $77.5( \pm 15.7)$ & 0.429 \\
\hline HR (bpm) & $84.0( \pm 20.0)$ & $86.3( \pm 15.3)$ & $85.9( \pm 16.1)$ & 0.636 \\
\hline RR (bpm) & $18.6( \pm 4.5)$ & $18.9( \pm 4.4)$ & $18.8( \pm 4.4)$ & 0.275 \\
\hline $\mathrm{BT}\left({ }^{\circ} \mathrm{C}\right)$ & $36.2( \pm 0.7)$ & $36.3( \pm 0.7)$ & $36.3( \pm 0.7)$ & 0.244 \\
\hline
\end{tabular}

Values are presented as mean \pm standard deviation or number (\%).

TBI: traumatic brain injury, BAC: blood alcohol concentration, GCS: Glasgow Coma Scale, ICU: intensive care unit, ED: emergency department, MVC: motor vehicle collison, SBP: systolic blood pressure, DBP: diastolic blood pressure, HR: heart rate, RR: respiratory rate, BT: body temperature. 
threshold at which significant disturbances of motor and cognitive functions begin $[7,11]$. Age, sex, vital signs, trauma mechanism, GCS score, head CT results, BAC, final diagnosis, and disposition were recorded as mandatory medical data. This study was approved by the Institutional Review Board (H-1911-1080-001).

\section{Measures}

The GCS score was initially obtained in the emergency department by an emergency physician, and GCS scores were categorized as 15, 13-14, 9-12, and 3-8. We defined a difference of at least 1 point in the GCS as clinically significant $[12,16]$. BAC is routinely measured in all patients with trauma who have the potential for alcohol intoxication in the emergency department at the National Medical Center. BAC results were expressed in milligrams per deciliter. Based on the resultant physiological changes, BAC was classified into five categories to examine its effect on GCS scores (BAC $<100,100$ to $<150,150$ to $<250$, 250 to $<300$, and $\geq 300 \mathrm{mg} / \mathrm{dL})[10,19]$.

It is recommended to perform non-contrast head CT in all patients with head trauma in case of alcohol intoxication in the emergency department $[20,21]$, and these guidelines were followed in this study. The interpretation of head CT scans was confirmed by neuroradiologists. The TBI group included patients with an acute intracranial injury (epidural hemorrhage $[\mathrm{EDH}]$, subdural hemorrhage $[\mathrm{SDH}]$, subarachnoid hemorrhage [SAH], intracerebral hemorrhage $[\mathrm{ICH}]$, contusion, or cerebral edema), and the non-TBI group included those with no signs of an intracranial injury on head CT. To control for the influence of injury severity, TBI severity was graded using the head Abbreviated Injury Score (AIS), an anatomical head injury score based on either operative or CT scan findings. The AIS has a range of 1 to 6 , from minor injuries to maximal and lethal injuries, and the AIS-2005 was used.

\section{Statistical analysis}

Variables related to patients and injuries are presented as percentages and mean \pm standard deviation. To assess whether the effects of alcohol on consciousness were influenced by brain injury, patients were classified into the TBI and non-TBI groups and evaluated accordingly. In the TBI group, a subgroup analysis was performed using the AIS to confirm the effect of the severity of brain injury on the GCS score. The Spearman correlation coefficient (r) was calculated to investigate the relationships among BAC, AIS, and GCS scores. To compare continuous variables, the Student $t$-test or Mann-Whitney $U$ test was

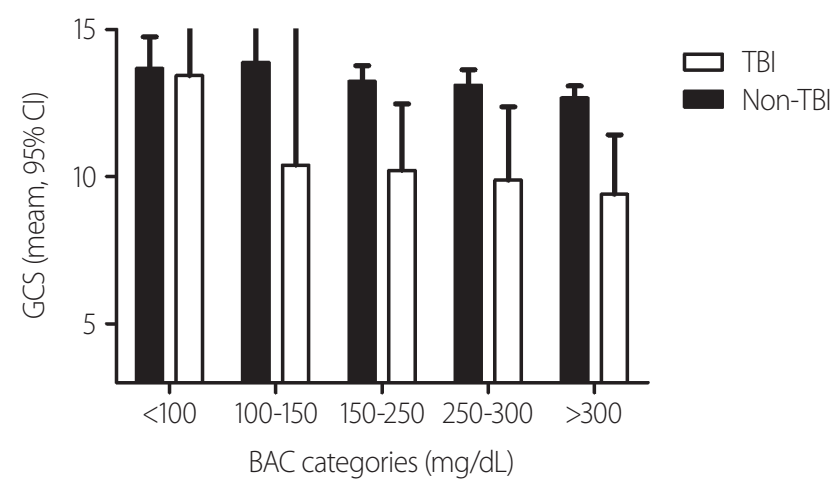

Fig. 2. Mean GCS scores by BAC categories between the TBI and nonTBI groups. GCS: Glasgow Coma Scale, BAC: blood alcohol concentration, Cl: confidential interval, TBl: traumatic brain injury.

Table 2. Mean GCS scores by BAC category between TBI and non-TBI patients

\begin{tabular}{|c|c|c|c|c|}
\hline \multirow[b]{2}{*}{ BAC (mg/dL) } & \multicolumn{2}{|c|}{ TBI } & \multicolumn{2}{|c|}{ Non-TBI } \\
\hline & Mean GCS & Number & Mean GCS & Number \\
\hline$<100$ & $13.4( \pm 4.2)$ & $7(10.9)$ & $13.7( \pm 1.0)$ & $6(1.8)$ \\
\hline 100 to $<150$ & $10.4( \pm 6.3)$ & $5(7.8)$ & $13.9( \pm 2.7)$ & $17(5.1)$ \\
\hline 150 to $<250$ & $10.2( \pm 4.7)$ & 19 (29.7) & $13.2( \pm 2.4)$ & $78(23.5)$ \\
\hline 250 to $<300$ & $9.9( \pm 4.7)$ & $16(25.0)$ & $13.1( \pm 2.2)$ & $72(21.7)$ \\
\hline$\geq 300$ & $9.4( \pm 3.9)$ & 17 (26.6) & $12.7( \pm 2.7)$ & 159 (47.9) \\
\hline
\end{tabular}

Values are presented as number (\%) or mean (standard deviation).

TBl: traumatic brain injury, BAC: blood alcohol concentration, GCS: Glasgow Coma Scale. 
used depending on the presence or absence of a normal distribution, and the chi-square test was used to compare categorical variables. Ordinal logistic regression was used in the multivariate analysis to determine whether BAC and head AIS were independent predictors of a lower GCS score as a dependent variable. Odds ratios (ORs) were calculated for each BAC category using a BAC $\leq 100 \mathrm{mg} / \mathrm{dL}$ as the reference group. A $p$-value $<0.05$ was considered to indicate statistical significance. Data were analyzed using SPSS version 21.0 (IBM Corp., Armonk, NY, USA) and R version 3.3.3.

\section{RESULTS}

Table 1 shows the demographic characteristics and clini-

Table 3. Distribution of head injury severity in TBI patients

\begin{tabular}{|lccc|}
\hline AIS grade & Mean GCS & Mean BAC & Number \\
\hline AIS 1 & $13.0( \pm 2.0)$ & $207.2( \pm 103.5)$ & $3(4.7)$ \\
AIS 2 & $12.4( \pm 2.6)$ & $255.7( \pm 96.8)$ & $8(12.5)$ \\
AIS 3 & $11.9( \pm 3.9)$ & $257.6( \pm 91.3)$ & $20(31.3)$ \\
AIS 4 & $10.7( \pm 4.9)$ & $214.2( \pm 87.0)$ & $15(23.4)$ \\
AIS 5 & $6.7( \pm 4.1)$ & $241.3( \pm 95.1)$ & $18(28.1)$ \\
\hline
\end{tabular}

Values are presented as number (\%) or mean (standard deviation). TBI: traumatic brain injury, BAC: blood alcohol concentration, GCS: Glasgow Coma Scale, AIS: Abbreviated Injury Score.

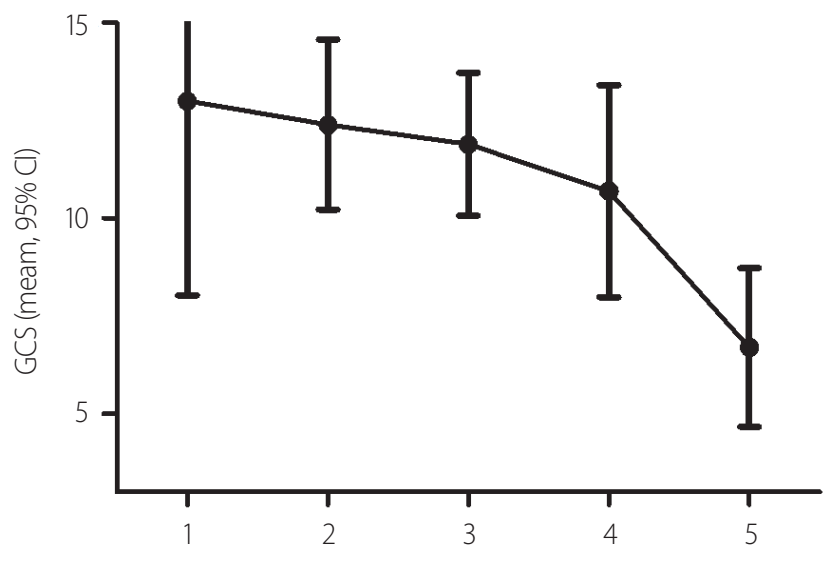

A

AIS cal information of the 396 patients included in the study. The TBI group, which included patients who had an intracranial injury on CT, consisted of 64 patients (16.2\%). The CT findings of TBI were as follows: SDH, 28 (43.8\%); SAH, 13 (20.3\%); EDH, 6 (9.4\%); contusion, 7 (10.9\%); ICH, 4 (6.3\%); and SDH and SAH, 6 (9.4\%). The mean BAC was $285.3 \pm 89.6 \mathrm{mg} / \mathrm{dL}$ in all patients, and was significantly higher in the non-TBI group $(293.4 \pm 87.3 \mathrm{mg} /$ $\mathrm{dL})$ than in the TBI group $(242.8 \pm 89.9 \mathrm{mg} / \mathrm{dL})$. The number of patients with a BAC $\geq 300 \mathrm{mg} / \mathrm{dL}$ was significantly higher in the non-TBI group. The mean GCS score was significantly lower in the TBI group $(10.3 \pm 4.6)$ than in the non-TBI group $(13.0 \pm 2.5)(p<0.001)$. Comparing the difference between the TBI and non-TBI groups for each GCS category, the only significant difference was found in the GCS 3-8 category, corresponding to severe brain injuries. A negative correlation was found between the GCS score and BAC, with a more significant correlation in patients with TBI (TBI, $r=-0.261, p=0.037$; non-TBI, $r=-$ $0.181, p=0.001)$. Falling $(89.1 \%)$ was the most common mechanism of injury, and pedestrian accidents were more common in the TBI group (9.4\% vs. $1.2 \%)$. Age, sex, and vital signs did not show significant differences between the two groups.

Within-group comparisons in patients with TBI for the 5 BAC categories showed that the mean GCS score significantly decreased with as BAC increased (Table 2, Fig. 2). With the mean GCS score in the BAC $<100 \mathrm{mg} / \mathrm{dL}$ cat-

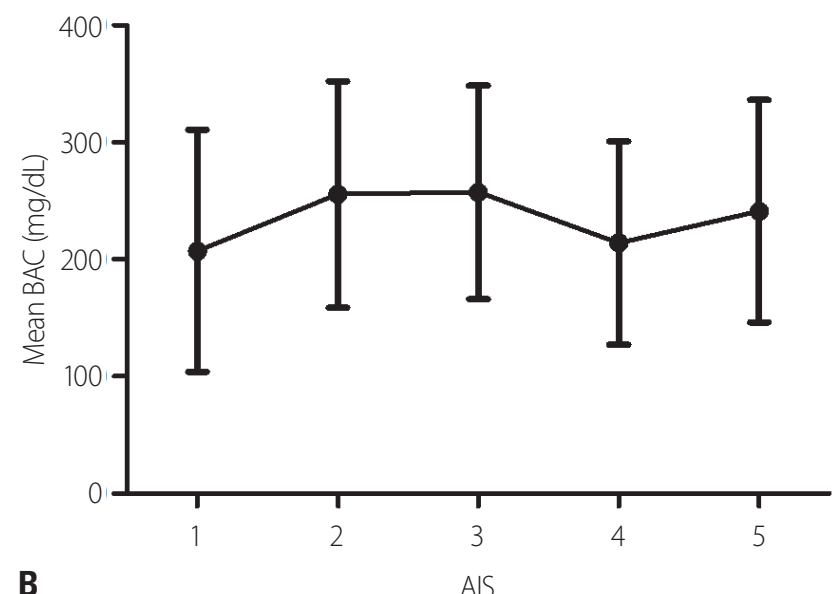

Fig. 3. (A) Relationship between AIS and GCS. There was a significant correlation between AIS and GCS scores ( $r=-0.436, p<0.001)$. (B) Relationship between AIS and BAC. There was no significant correlation between AIS and BAC ( $r=-0.066, p=0.607)$. AIS: Abbreviated Injury Score, GCS: Glasgow Coma Scale, BAC: blood alcohol concentration. 
egory as a reference value, the mean GCS score between each BAC category and the BAC $<100 \mathrm{mg} / \mathrm{dL}$ category showed a significant reduction of $\geq 1$ point. In contrast, the within-group comparisons in patients without TBI according to the five BAC categories revealed no significant differences in GCS scores.

The interactions between injury severity, BAC, and GCS scores in the TBI group are shown in Table 3 and Fig. 3. The GCS score was negatively correlated with head AIS in the TBI group $(r=-0.436, p<0.001)$. For patients with an AIS $\geq 4$ (severe), the mean GCS score according to AIS grades showed a significant reduction by $\geq 1$ point, and patients with an AIS of 5 (critical) showed the sharpest reduction in the GCS score, with a mean of $<7$. However, there was no significant correlation between BAC and AIS

Table 4. Ordinal logistic regression analysis with a lower GCS score as the dependent variable

\begin{tabular}{|lrll|}
\hline Variables & OR & 95\% Cl & $p$-value \\
\hline TBl patients & & & \\
BAC $(\mathrm{mg} / \mathrm{dL})$ & 1.01 & $1.00-1.01$ & 0.006 \\
100 to $<150$ & Ref & & \\
150 to $<250$ & 6.35 & $0.39-189.40$ & 0.209 \\
250 to $<300$ & 15.26 & $2.21-320.50$ & 0.021 \\
$\geq 300$ & 17.88 & $2.34-378.44$ & 0.015 \\
AlS & 33.60 & $4.22-728.21$ & 0.004 \\
1=minor & 1.93 & $1.30-2.98$ & 0.002 \\
2=moderate & 1.38 & $0.15-14.50$ & 0.776 \\
3=serious & 1.28 & $0.17-11.78$ & 0.812 \\
4=severe & 1.44 & $0.17-14.00$ & 0.732 \\
5=critical & 15.72 & $1.77-173.18$ & 0.015 \\
Non-TBl patients & & & \\
BAC (mg/dL) & 1.00 & $1.00-1.01$ & 0.004 \\
$<100$ & Ref & & 0.942 \\
100 to $<150$ & 0.20 & $0.03-1.08$ & 0.064 \\
150 to $<250$ & 0.79 & $0.21-3.12$ & 0.734 \\
250 to $<300$ & 0.85 & $0.22-3.34$ & 0.808 \\
$\geq 300$ & 1.04 & $0.28-4.00$ & 0.942 \\
\hline
\end{tabular}

TBI: traumatic brain injury, BAC: blood alcohol concentration, GCS: Glasgow Coma Scale, AIS: Abbreviated Injury Score, OR: odds ratio, Cl: confidential interval. $(\mathrm{r}=-0.066, p=0.607)$.

Based on the abovementioned results, multivariate ordinal logistic regression was performed to identify whether BAC and AIS were associated with lower GCS scores (Table 4). The results showed that a higher BAC was significantly related to a lower GCS score in patients with TBI. When the BAC was $\geq 150 \mathrm{mg} / \mathrm{dL}$, the ORs for a lower GCS score were significant as BAC increased in the TBI group. AIS did not predict a reduction in the GCS score as severity increased, except in critical cases. In the nonTBI group, higher BAC did not predict a reduction in the GCS score.

\section{DISCUSSION}

The main result of the study is that the GCS score was reduced due to the effects of alcohol in patients with TBI, but not in patients without TBI. In our analysis, a reduction in the GCS score was observed with increasing BAC only in the TBI group, while this result was not found in the non-TBI group. Of particular note, in the TBI group, when BAC was $\geq 150 \mathrm{mg} / \mathrm{dL}$, the GCS score was significantly lower. In contrast, in the non-TBI group, there was no significant reduction in GCS score despite BAC being high enough to affect consciousness.

In previous studies, the relationship between BAC and GCS scores in patients with TBI was inconclusive. A reduction in the GCS score in patients with high BAC has been reported in some studies [8-11]. Rundhaug et al. [10] reported that a high BAC reduced the GCS score only in patients with moderate and severe TBI with CT findings that did not suggest elevated intracranial pressure (ICP). Rønning et al. [17] also found that higher BACs were associated with increased likelihoods of a low GCS score and accompanying significant brain injury. A study by Shahin et al. [11] analyzing patients with TBI admitted to the neurosurgical intensive care unit demonstrated that higher BACs were associated with significantly lower GCS scores and confirmed that the GCS scores changed to a significant extent in the intoxicated group (median score $=3$ ) after hospitalization. These effects are explained by CNS deterioration caused by the synergistic effects of brain damage and alcohol intoxication in the initial phase 
after brain injury [14].

Contrary to the general expectation of clinicians that alcohol intoxication in patients with brain injury would decrease consciousness, other studies have shown that BAC was not associated with GCS reduction in patients with TBI [12-16]. In a study of 1,075 patients with blunt TBI by Sperry et al. [16], alcohol intoxication did not show a significant association with lower GCS scores in patients with TBI, and even high BACs (>250 mg/dL) did not affect the GCS score. In another large study of 108,929 patients who were admitted to trauma centers across the United States, alcohol intoxication was not associated with lower GCS scores in patients with TBI [12]. However, in that study, it was found that alcohol intoxication reduced the GCS score by $\geq 1$ in patients with severe trauma (ISS $>25$ ) in the non-TBI or minor TBI group. Lange et al. [14] also did not demonstrate an association between BAC and GCS scores, but found that the GCS score was reduced by $\geq 1$ in patients with abnormal CT results with a BAC $\geq 200 \mathrm{mg} / \mathrm{dL}$. Other studies have similarly reported that BACs $>200 \mathrm{mg} / \mathrm{dL}$ were associated with lower GCS scores than found in patients with lower BACs $[8,22,23]$. However, although a high BAC can affect consciousness, Minion found that approximately $88 \%$ of patients with a $\mathrm{BAC} \geq 400 \mathrm{mg} / \mathrm{dL}$ did not exhibit significant changes in consciousness [24].

These contradictory findings on the effects of alcohol on consciousness suggest that measuring BAC is not a suitable method for objectively assessing the status of alcohol intoxication. This is because individual differences in alcohol tolerance vary widely and are influenced by functional (e.g., learned tolerance, environment-dependent tolerance), metabolic, and genetic factors [14]. Moreover, alcohol tolerance is determined by the amount and frequency of alcohol consumption, metabolic rate, liver function status, and currently used medications [24]. Other factors may cause deterioration of consciousness in patients with trauma, such as associated injuries, the presence of shock, hypothermia, hypoxia, hypercapnia, or other CNS drugs. Another confounding factor is that GCS is not a reliable and sensitive method of assessing the severity of TBI, particularly in patients with alcohol intoxication.

The main limitation in evaluating the effects of alcohol on the GCS score in patients with TBI is whether the influence on consciousness caused by brain injury severity has been adjusted. The reason for this is that CNS depression from alcohol could likely be attenuated by the brain injury in patients with severe injuries [4]. To adjust for the severity of brain injuries, several methods have been used. One approach is to compare the presence and absence of brain injury between normal CT and abnormal CT groups [14]. Other studies have used head AIS, based on the degree of anatomical injury $[12,16,17]$, and another method is to use the Rotterdam CT score, a classification based on CT findings [10]. Sperry et al. [16] did not show a difference in GCS score according to alcohol intoxication within the same head AIS group, but in patients with an AIS of 5 , the GCS score was significantly (1.4 points) lower in patients with alcohol intoxication. However, that study did not provide additional information on BAC. In Rønning's study [17], a higher BAC was associated with severe GCS scores and significant brain injury. Therefore, it is difficult to assume that the reduction in GCS score was simply caused by the effects of alcohol. Rundhaug et al. [10] used the Rotterdam CT score, which classified the severity of anatomical brain injuries based on CT findings, and showed that the GCS score was reduced as BAC increased in patients without signs of elevated ICP (Rotterdam score 1-3). In contrast, a GCS score reduction was not observed in patients with CT findings showing signs of elevated ICP (midline shift and/or compressed or absent basal cisterns, Rotterdam score 4-6), indicating that the effects of alcohol were attenuated by severe brain injuries. In our study, with increasing head AIS, the GCS score showed a tendency to decrease, and AIS was associated with a lower GCS $(\mathrm{r}=-0.436, p<0.001)$ in patients with TBI. However, in ordinal logistic regression analyses, no significant association was found between higher AIS and lower GCS scores, except for patients with critical injuries. Although the severity of the brain injury is the most important contributor to a low GCS score, Sperry et al. [16] also did not show a significant reduction in the GCS score, except in patients with an AIS of 5. Therefore, if the GCS score is $\leq 8$ in a patient with head trauma, even if he or she has alcohol intoxication, clinicians should initially assume that the impaired consciousness is due to a severe brain injury. 


\section{Limitations}

This study was conducted at a single institution and may only reflect regional patient characteristics. As a common limitation of retrospective studies, it is possible that the results were biased by uncontrolled confounding variables. Moreover, alcohol testing could have been conducted selectively for certain patients, so the analysis may have been influenced by selection bias. The reliability of the GCS scores determined in the emergency department may be somewhat questionable because an accurate GCS evaluation can be difficult or confusing due to alcohol intoxication. However, as alcohol metabolism progresses over time, follow-up BAC tests would be helpful for understanding the effects of alcohol on GCS scores. The sample size of the TBI group with abnormal CT findings was relatively small compared to that of other studies, and a larger sample size is needed for future research.

\section{CONCLUSION}

In this study, we found that the influence of alcohol on patients with head trauma depended on the presence of a brain injury. A significant association between a higher BAC and a lower GCS score was only observed in patients with TBI. Moreover, when the severity of brain injury was critical, sharply lower GCS scores were found. Therefore, if a severe brain injury is suspected with in a head trauma patient with a GCS score $\leq 8$ and alcohol intoxication, prompt diagnosis and intensive care should be performed without delay. Furthermore, it is recommended that, if a patient's consciousness is more strongly reduced than would be expected given the CT findings of brain injury, clinicians should thoughtfully consider whether invasive procedures should be performed immediately, considering that this finding could reflect an additional and transient effect of alcohol on TBI.

\section{REFERENCES}

1. Ghajar J. Traumatic brain injury. Lancet 2000;356:923-9.

2. Tagliaferri F, Compagnone C, Korsic M, Servadei F, Kraus J. A systematic review of brain injury epidemiology in Europe. Acta
Neurochir (Wien) 2006;148:255-68; discussion 268.

3. Thurman DJ, Alverson C, Dunn KA, Guerrero J, Sniezek JE. Traumatic brain injury in the United States: a public health perspective. J Head Trauma Rehabil 1999;14:602-15.

4. Grote S, Böcker W, Mutschler W, Bouillon B, Lefering R. Diagnostic value of the Glasgow Coma Scale for traumatic brain injury in 18,002 patients with severe multiple injuries. J Neurotrauma 2011;28:527-34.

5. Teasdale G, Jennett B. Assessment of coma and impaired consciousness. A practical scale. Lancet 1974;2:81-4.

6. Sloan EP, Zalenski RJ, Smith RF, Sheaff CM, Chen EH, Keys NI, et al. Toxicology screening in urban trauma patients: drug prevalence and its relationship to trauma severity and management. J Trauma 1989;29:1647-53.

7. Johnston JJ, McGovern SJ. Alcohol related falls: an interesting pattern of injuries. Emerg Med J 2004;21:185-8.

8. Alexander S, Kerr ME, Yonas H, Marion DW. The effects of admission alcohol level on cerebral blood flow and outcomes after severe traumatic brain injury. J Neurotrauma 2004;21:575-83.

9. Brickley MR, Shepherd JP. The relationship between alcohol intoxication, injury severity and Glasgow Coma Score in assault patients. Injury 1995;26:311-4.

10. Rundhaug NP, Moen KG, Skandsen T, Schirmer-Mikalsen K, Lund SB, Hara S, et al. Moderate and severe traumatic brain injury: effect of blood alcohol concentration on Glasgow Coma Scale score and relation to computed tomography findings. J Neurosurg 2015;122:211-8.

11. Shahin H, Gopinath SP, Robertson CS. Influence of alcohol on early Glasgow Coma Scale in head-injured patients. J Trauma 2010;69:1176-81; discussion 1181.

12. Stuke L, Diaz-Arrastia R, Gentilello LM, Shafi S. Effect of alcohol on Glasgow Coma Scale in head-injured patients. Ann Surg 2007;245:651-5.

13. Hall D, Riley J, Swann I. Can alcohol intoxication be excluded as the cause of confusion following head injury? Scott Med J 2005;50:24-6.

14. Lange RT, Iverson GL, Brubacher JR, Franzen MD. Effect of blood alcohol level on Glasgow Coma Scale scores following traumatic brain injury. Brain Inj 2010;24:919-27.

15. Pories SE, Gamelli RL, Vacek P, Goodwin G, Shinozaki T, Harris F. Intoxication and injury. J Trauma 1992;32:60-4.

16. Sperry JL, Gentilello LM, Minei JP, Diaz-Arrastia RR, Friese RS, Shafi S. Waiting for the patient to "sober up": effect of alcohol intoxication on Glasgow Coma Scale score of brain injured pa- 
tients. J Trauma 2006;61:1305-11.

17. Rønning P, Gunstad PO, Skaga NO, Langmoen IA, Stavem K, Helseth E. The impact of blood ethanol concentration on the classification of head injury severity in traumatic brain injury. Brain Inj 2015;29:1648-53.

18. Roozenbeek B, Lingsma HF, Perel P, Edwards P, Roberts I, Murray GD, et al. The added value of ordinal analysis in clinical trials: an example in traumatic brain injury. Crit Care 2011;15:R127.

19. Walls RM, Hockberger R, Gausche-Hill M. Rosen's emergency medicine: concepts and clinical practice 9th edition. Philadelphia:Elsevier;2018.

20. Easter JS, Haukoos JS, Claud J, Wilbur L, Hagstrom MT, Cantrill S, et al. Traumatic intracranial injury in intoxicated patients with minor head trauma. Acad Emerg Med 2013;20:753-60.

21. Haydel MJ, Preston CA, Mills TJ, Luber S, Blaudeau E, DeBlieux PM. Indications for computed tomography in patients with minor head injury. N Engl J Med 2000;343:100-5.

22. Galbraith S, Murray WR, Patel AR, Knill-Jones R. The relationship between alcohol and head injury and its effect on the conscious level. Br J Surg 1976;63:128-30.

23. Jagger J, Fife D, Vernberg K, Jane JA. Effect of alcohol intoxication on the diagnosis and apparent severity of brain injury. Neurosurgery 1984;15:303-6.

24. 24. Minion GE, Slovis CM, Boutiette L. Severe alcohol intoxication: a study of 204 consecutive patients. J Toxicol Clin Toxicol 1989;27:375-84. 